NASZA DERMATOLOGIA Online OUR DERMATOLOGY Online

Source of Support: Nil

Competing Interests: None

\section{NEUTROPHILIC MYOSITIS ASSOCIATED WITH PYODERMA GANGRENOSUM IN A BREAK-DANCER}

\author{
Hisashi Tamiya, Hiromi Kobayashi, Kaori Hoshi, Yui Horiguchi, \\ Kurooka Sadahiro, Akiko Naruse, Shigeto Yanagihara, \\ Daisuke Tsuruta
}

Department of Dermatology, Osaka City University Graduate School of Medicine, Osaka, Japan

Corresponding author: Hisashi Tamiya, $\mathrm{MD}, \mathrm{PhD}$

hi-ku@med.osaka-cu.ac.jp

\begin{abstract}
Neutrophilic myositis is an extremely rare condition, cases of which have been reported in association with neutrophilic dermatosis, inflammatory bowel disease and malignant hematological disease. The disorder is histologically characterized by a sterile infiltration of neutrophils throughout muscle, with necrosis of muscle fibres. We here report the case of a young male who also had associated pyoderma gangrenosum, and who presented with necrotizing fasciitis-like manifestations. In this case, although there were no other underlying disorders, compulsive exertional stress due to break-dancing was thought to be a precipitant. Debridement of the necrotic tissues combined with oral corticosteroid treatment was effective.
\end{abstract}

Key words: neutrophilic myositis; pyoderma gangrenosum; hard exercise

Cite this article:

Hisashi Tamiya, Hiromi Kobayashi, Kaori Hoshi, Yui Horiguchi, Kurooka Sadahiro, Akiko Naruse, Shigeto Yanagihara, Daisuke Tsuruta: Neutrophilic myositis associated with pyoderma gangrenosum in a break-dancer. Our Dermatol Online. 2013; 4(4): 484-486.

\section{Introduction}

Neutrophilic myositis, which is extremely rare, is characterized by a histologically sterile infiltration of neutrophils throughout the muscle accompanied by disruption of the muscle architecture and numerous areas of muscle fiber necrosis [1]. This condition has been reported as an extracutaneous manifestation of neutrophilic dermatosis, and also been associated with inflammatory bowel disease and with hematological malignancies [1-6]. Here, we report a young male with neutrophilic myositis of the lateral aspect of the knee, accompanied by pyoderma gangrenosum. A clinical characteristic of our case was that exercise-induced stress on the knee brought on by compulsive break-dancing was thought to be a trigger of the onset.

\section{Case Report}

A 27-year-old man came to our hospital with a complaint of a one-month history of intractable pain and swelling of his right knee. He had experienced prior, similar ,phlegmonous' swelling of his right knee, with three episodes over the past three years. Previously, oral or intravenous antibiotics relieved his symptoms, but this time, his eruption failed to respond to treatment with several courses of oral antibiotics that included cephems, new-generation quinolones, and tetracycline. When asked about his habits, he disclosed that he had started to break- dance at the age of nineteen, and that in the past the symptoms that affected his right knee consistently appeared after straining his knees during vigorous dancing. At his visit, his right knee was remarkably swollen with marked black cutaneous necrosis and skin ulcers (Fig. 1a). Body temperature was elevated to $38.8 \mathrm{oC}$. Laboratory examination showed the following: white blood cell count, 16,800/ $\mu$ l (neutrophils: $77.6 \%$, lymphocytes: $14.5 \%$, eosinophils: 1.6\%); C-reactive protein, $10.49 \mathrm{mg} /$ dl; creatine phosphokinase, $560 \mathrm{IU} / \mathrm{L}$; procalcitonin negative. Other tests, such as liver and renal function, quantitative serum immunoglobulins, blood cultures, urinalysis, and viral serology (cytomegalovirus, Epstein-Barr virus, human immunodeficiency virus), rheumatoid factor, antinuclear antibodies, anticardiolipin and antiphospholipid antibodies, and antineutrophil cytoplasmic antibodies were all normal or negative. Magnetic resonance imaging showed that inflammation involved not only the subcutaneous tissues but also the right musculus quadriceps femoris. We considered this condition as necrotizing fasciitis. We therefore performed emergency debridement of the necrotic tissue including the skin and muscles. Histological study of the debrided tissues revealed marked inflammatory infiltrates, composed predominantly of neutrophils that extended throughout all layers of the skin and involved muscle fibers, accompanied by disruption of the muscle architecture and numerous areas of muscle fiber necrosis (Fig. 2a, b). 

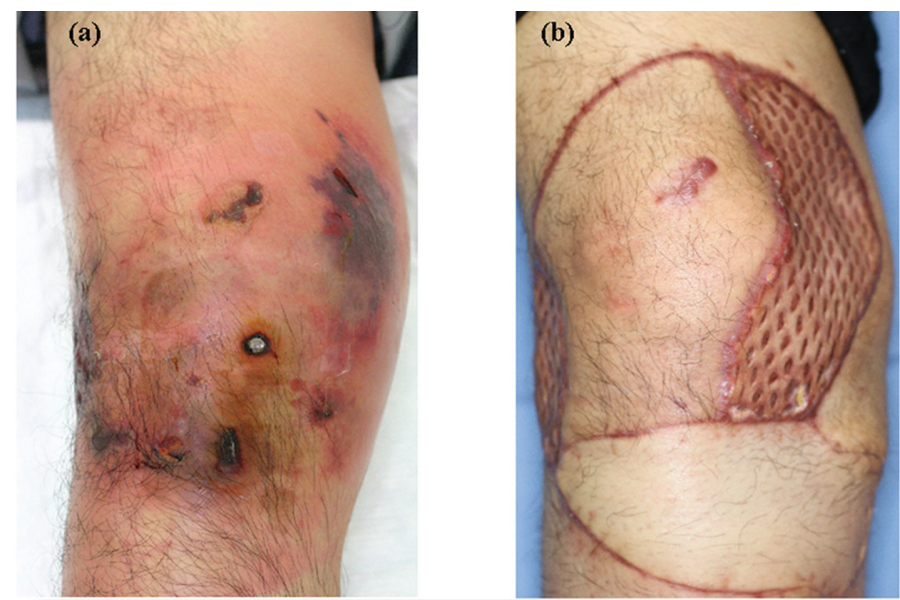

Figure 1. Clinical appearance (a) before, and (b) six months after treatment with debridement and oral steroid. (a) The right knee demonstrates remarkable swelling with marked, black cutaneous necrosis and skin ulcers. (b) After debridement and administration of oral steroids, the ulcerative lesion on the right knee healed with good granulation tissue, and could then be managed successfully with a skin graft and pedicle skin flap, without reactivation.

However, tissue cultures for bacteria, fungi, acid-fast microorganisms and parasitic amoebae were all negative. On the basis of these findings we made a final diagnosis of neutrophilic myositis associated with pyoderma gangrenosum. Investigation for an underlying illness, such as inflammatory bowel disease or a myeloproliferative disorder, (respectively by fibreoptic colonoscopy and bone marrow aspiration) revealed no abnormal findings. After debridement, we started treatment with oral methylprednisolone at a dosage of 40mg per day. His postoperative wound subsequently healed with good granulation tissue and, after one month, we performed a two-stage operation to address the residual ulcer successfully with the combination of a skin graft and pedicle-based skin flap. The dose of oral steroid could be tapered to $10 \mathrm{mg}$ per day for about six months, and there has been no exacerbation (Fig. 1b).
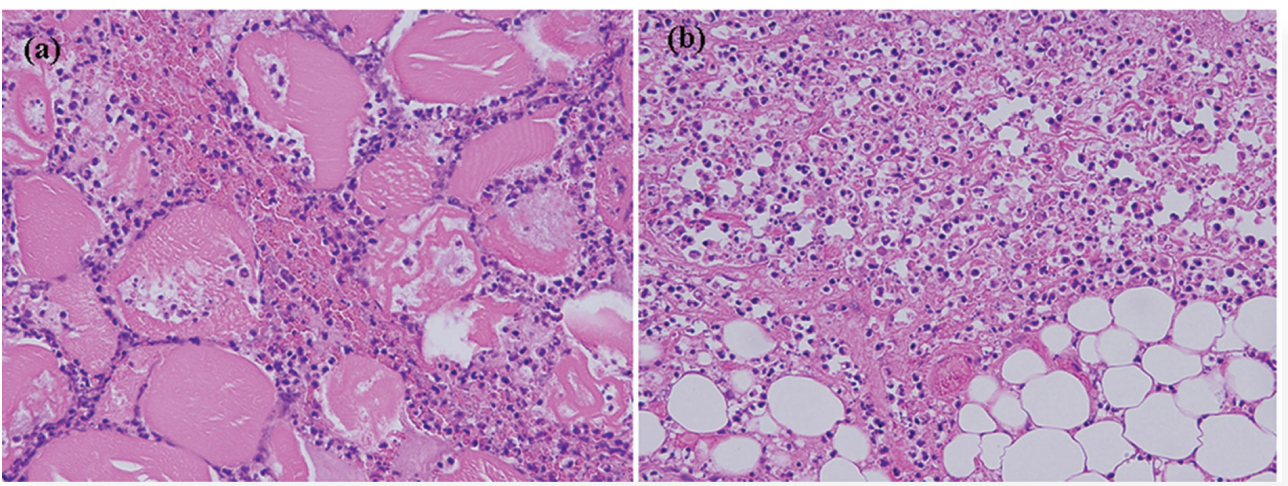

Figure 2. Histological study of the debrided tissues demonstrates severe inflammatory infiltrates, composed predominantly of neutrophils that extend throughout both the right musculus quadriceps femoris (a) and the skin of the same lesion (b). The muscle lesion was accompanied by disruption of the muscle architecture and numerous areas of muscle fiber necrosis. (Haematoxylin and Eosin stain, original magnification $\times 400$ ).

\section{Discussion}

Neutrophilic myositis is an extremely rare condition. To the best of our knowledge, only six cases have been reported, apart from ours [1-6]. The cases of neutrophilic myositis are summarized in Table I. The ratio of males to females is 5: 2 , and the favorite involved sites were extremities. Three cases were associated with a neutrophilic dermatosis such as pyoderma gangrenosum [1] or Sweet's syndrome [2,3], and all of these cases coexisted with underlying leukaemia. The other cases had no cutaneous involvement, but were accompanied by underlying diseases, such as inflammatory bowel disease $[4,5]$ or a myeloproliferative disorder [6]. Although coexistent pyoderma gangrenosum was seen in our case, there was no other underlying illness, in contrast to the reported cases [13]. We should however be vigilant for the later occurrence of such a disorder, particularly inflammatory bowel disease or a myeloproliferative disorder.

The diagnosis of neutrophilic myositis must be based on both histological demonstrations of intense neutrophilic infiltration throughout the affected muscles, with necrosis of muscle fibers, and exclusion of other muscle diseases, for example, polymyositis, dermatomyositis, inclusion body myositis, and pyomyositis [1]. 


\begin{tabular}{|c|c|c|c|c|c|c|}
\hline Authors(s) [Ref.] & Sex & Age (years) & Coexisting disease & $\begin{array}{l}\text { Involved site } \\
\text { of myositis }\end{array}$ & Treatment & Prognosis \\
\hline Marie I et al. [1] & Male & 65 & $\begin{array}{l}\text { pyoderma gangrenosum } \\
\text { acute myelogeneous } \\
\text { leukemia }\end{array}$ & $\begin{array}{l}\text { bilateral lower, upper } \\
\text { limbs }\end{array}$ & $\begin{array}{l}\text { Methylprednisolone } \\
\text { chemotherapy }\end{array}$ & death \\
\hline Melinkeri SR et al. [2] & Female & 6 & acute myeloid leukemia & left thigh & $\begin{array}{l}\text { Methylprednisolone } \\
\text { chemotherapy }\end{array}$ & death \\
\hline Attias D et al. [3] & Female & 60 & $\begin{array}{l}\text { Sweet's syndrome } \\
\text { myeloblastic leukemia }\end{array}$ & $\begin{array}{l}\text { bilateral thighs, left } \\
\text { shoulder }\end{array}$ & $\begin{array}{l}\text { Methylprednisolone } \\
\text { chemotherapy }\end{array}$ & death \\
\hline Alawneh K et al. [4] & Male & 42 & celiac disease & $\begin{array}{l}\text { right thigh, left lowe- } \\
\text { re limb }\end{array}$ & Methylprednisolone & remission \\
\hline Qureshi JA et al. [5] & Male & 36 & ulcerative colitis & $\begin{array}{l}\text { right shoulder, lower } \\
\text { extremities }\end{array}$ & Methylpredniso1one & remission \\
\hline Kim MK at al. [6] & Male & 35 & acute myeloid leukemia & upper arm & Methylpredniso1one & remission \\
\hline our case & Male & 27 & pyoderma gangrenosum & right thigh & $\begin{array}{l}\text { Methylprednisolone } \\
\text { debridement }\end{array}$ & remission \\
\hline
\end{tabular}

Table I. Summary of past cases of neutrophilic myositis.

Our case could finally be diagnosed as neutrophilic myositis related to pyoderma gangrenosum for the following reasons: the simultaneous onset of both neutrophilic myositis and pyoderma gangrenosum; negative stains and bacterial cultures of muscle and skin biopsy specimens; extensive, negative investigation for other causes of myositis such as infectious and connective tissue disorders; the efficacy of systemic steroids; and the ineffectiveness of broad-spectrum antibiotic therapy.

The etiology of neutrophilic myositis remains unclear. Heterogeneous factors, such as allergy to pathogenic organisms, traumatic injury and immunological abnormality due to coexisting disorders may be associated, as well as pyoderma gangrenosum [7]. The present case is the first in which compulsive exercise-induced stress on the knee due to breakdancing was a potentially causative trigger. This observation suggests that damage to or degeneration of muscle tissue induced by compulsive exercise may induce an abnormal, neutrophilic inflammatory reaction without any underlying immunological imbalance.

Finally, therapy for neutrophilic myositis has not been established. Based on the cases described, including our case, systemic treatment with moderate-to-high dose steroids seems effective [1-6]. Furthermore, a coexisting myeloproliferative disorder seems to indicate a poor prognosis $[1-3,6]$.

\section{REFERENCES}

1. Marie I, Levesque H, Joly P, Reumont G, Courville P, Baudrimont $\mathrm{M}$, et al: Neutrophilic myositis as an extracutaneous manifestation of neutrophilic dermatosis. J Am Acad Dermatol. 2001;44:137-9.

2. Melinkeri SR, Gupta RK, Dabadghao S: A Sweet-like syndrome manifesting as gingival hyperplasia and myositis without cutaneous involvement. Ann Hematol. 2002;81:397-8.

3. Attias D, Laor R, Zuckermann E, Naschitz JE, Luria M, Misselevitch I, et al: Acute neutrophilic myositis in Sweet's syndrome: late phase transformation into fibrosing myositis and panniculitis. Hum Pathol. 1995;26:687-90.

4. Alawneh K, Ashley C, Carlson JA: Neutrophilic myositis as a manifestation of celiac disease: a case report. Clin Rheumatol. 2008;27Suppl 1:S11-3.

5. Qureshi JA, Staugaitis SM, Calabrese LH: Neutrophilic myositis: an extra-intestinal manifestation of ulcerative colitis. J Clin Rheumatol. 2002;8:85-8.

6. Kim MK, Park JW, Park SH, Bang SM, Chung JG, Ahn JY, et al: Neutrophilic myositis without cutaneous involvement as the first manifestation of acute myeloid leukemia. Korean J Intern Med. 2005;20:346-8.

7. Fowler JB, Callen JP: Pyoderma gangrenosum. Dermatol Clin. 1983;1:615-2.

Copyright by Hisashi Tamiya, et al. This is an open access article distributed under the terms of the Creative Commons Attribution License, which permits unrestricted use, distribution, and reproduction in any medium, provided the original author and source are credited. 